\title{
Yök Tez Merkezi ve Proquest Veri Tabanında Yer Alan Tarih Eğitimi Tezlerinin Değerlendirilmesi*
}
Evalution of History Education Dissertations Submitted to Council of Higher Education (Yok) Thesis Center and Proquest Database

DOI $=\underline{10.17556 / j \text { jef.06505 }}$

\author{
İbrahim TURAN ${ }^{* *}$, Hasan ASLAN ${ }^{* * *}$
}

Özet

Araştırmanın amacı Türkiye'de tarih eğitimi üzerine hazırlanmış tezleri araştırma konusu, kullanılan yöntem ve veri toplama araçları gibi farklı kriterler açısından değerlendirmek ve elde edilen sonuçları PROQUEST veri tabanında yer alan farklı ülkelere ait tarih eğitimi tezleri ile karşılaştırmaktır. Betimsel yöntemin kullanıldığı bu araştırmada, YÖK "Ulusal Tez Merkezi” ve PROQUEST veri tabanında yer alan tezler bilgisayar destekli tarama yöntemi ile farklı arama terimleri kullanılarak derlenmiştir. Derlenen tezler ülkelerine, yapılış yıllarına, üniversitelerine, düzeylerine (yüksek lisans veya doktora), konularına, kullanılan araştırma yöntemi, veri toplama araçları ve hedef kitlelerine göre içerik analizi yöntemi ile incelenmiştir. Araştırma sonucunda Türkiye'de tarih eğitimi üzerine yapılan tez çalışmalarının son 30 yılda giderek arttığ 1 görülmüştür. Türkiye'de yapılan tezlerde öğretim yöntemleri ve tutuma yönelik çalışmaların ağır bastığı, uluslararası tezlerde ise öğretim teknoloji ve materyalleri ile program ve ders kitaplarının daha sık çalışıldığı görülmüştür. Türkiye'de yapılan tezlerin büyük bölümünde nicel araştırma yöntemleri ve nicel veri toplama araçları kullanılırken, PROQUEST'te yer alan uluslararası tezlerde bunun aksine nitel araştırma yöntemleri ve buna bağlı veri toplama araçlarının daha sıklıkla kullanıldığı görülmüştür.

Anahtar Sözcük: Tarih Eğitimi, Yüksek Lisans, Doktora, Tez, Türkiye, PROQUEST

Abstract

The aim of the research is to evaluate history education theses prepared in Turkey in terms of content and the methods used, and to compare obtained results with theses prepared abroad and submitted to PROQUEST database. In this descriptive study, theses of history education were gathered from Council of Higher

\footnotetext{
* Bu çalışma II. Uluslararası Tarih Eğitim Sempozyumunda sunulan bildirinin genişletilmiş halidir.

** Yrd.Doç.Dr., İstanbul Üniversitesi, e-posta: ibrahim.turan@ istanbul.edu.tr

**** Yrd.Doç.Dr., Kafkas Üniversitesi, e-posta: hasanaslan@kafkas.edu.tr
} 
Education, "National Dissertation Center" and PROQUEST with computer-aided screening method by using various search terms. Compiled theses was evaluated using content analysis method according to country, date, university, level (masters or doctorate), content, research method and data collection instruments. Study shows that the number of dissertation on history education in Turkey has been increasing in the last 30 years. Teaching methods and attitudes are the two mostly studied subject in Turkish dissertations on the other hand educational technology, curriculum and textbooks are the mostly studies subject in international dissertations. Study also shows Turkish researchers are more often relied on quantitative research methods and data collection tools, by contrast qualitative research methods and related data collection instruments are mostly used by international researchers.

Keywords: History Education, Masters, PhD, Dissertation, Turkey, PROQUEST

\section{Giriş}

Tarihyazımı ile karşılaştırıldığında "tarih öğretimi” veya "tarih eğitimi" nispeten daha yeni kavramlardır. Yazının bulunmasıyla birlikte tarihyazımın ilk örnekleri görülmekle birlikte tarihin örgün eğitim kurumlarında ve geniş halk kitlelerine bağımsız bir ders olarak öğretilmesi sadece iki yüzyıllık bir geçmişe sahiptir (Demircioğlu, 2014). Bunun öncesinde tarih daha ziyade yönetici sınıfa hitap eden ve edebiyat veya coğrafya ile birlikte verilen bir ders olarak karşımıza çıkmaktadır. Klasik dönem Osmanlı medrese sisteminde tarih bağımsız bir akademik alan olarak müfredatta yer almamış ancak diğer derslerde okutulan kitaplar arasında tarihi konulara yer vermek suretiyle ögretilmiştir (Akyüz, 2014, s.69). Bu dönemde tarih kitapları "dinsel (Ümmet)" anlayışla yazılan daha ziyade edebi eser olarak sinıflandırabilecek kitaplardır (Demircioğlu, 2012, s.116-117). Tarihyazım ile tarih eğitimi arasındaki karşılıklı ilişki (Safran, 2008) ve özellikle tarih yazımının tarih öğretimi üzerindeki etkisinden (Demircioğlu, 2012) dolayı bu dönemde tarih öğretiminin hikâyeci bir anlayışa dayandığı ve ağırlıklı olarak peygamberler tarihi, Siyer-i Nebi gibi dini tarih konularının öğretildiği görülmektedir. Osmanlı Devleti'nde uygulanan bu tarih yazım ve öğretim sisteminin aynı dönemde dünyada hâkim olan anlayıştan farklı olmadığını belirtmek gerekir. Zira Avrupa'da aynı dönemde "teolojik tarih" anlayışı (Şirin, 2015, s.93-97) ile "edebi eserler" (Breisach, 2009, s.330) ortaya konmaktadır ve bu durum "profesyonel" veya "bilimsel" tarih 
(Öztürk, 2015, s.41-48) anlayışının hâkim olacağı 19. yy.'a kadar devam edecektir.

Örgün eğitim kurumlarında bağımsız bir ders olarak tarih öğretiminin ilk örneğine 19. Yüzyıl Fransa'sında rastlıyoruz. Fransa'da Napolyon'un emri ile 1802 yılında Türk eğitim sisteminde yer alan liselerin de (lycée) ilk örneği olan ortaöğretim kurumları kurulmuştur. Bu kurumlarla ilgili düzenlemenin yer aldığı 1808 eğitim yasasının (Decree of 17 March 1808) 1. Bölüm, 5. maddesinde liselerde okutulacak dersler arasında antik diller, retorik (belagat), mantık, matematik ve fiziksel bilimlerle birlikte tarih dersine de yer verilmiştir (Documents upon Napoleon, t.y.).

Avrupa'da kurulan modern eğitim kurumları Osmanlı Devletinde de karşıllk bulmuş ve 1869 Maarif-i Umumiye Nizamnamesi ile ilk düzenli okul müfredatı hazırlanmıştır. $\mathrm{Bu}$ düzenlemede tarih dersi müfredatın bir parçası olarak kabul edilmiştir. $\mathrm{Bu}$ tarihten itibaren Osmanlı Devleti ve Türkiye Cumhuriyetinde eğitimin her kademesinde tarih dersleri farklı isimler altında ve döneme göre farklı yaklaşımlarla hazırlanmış öğretim programları ile öğretilmeye devam etmiştir.

19. yy.da Avrupa'da ortaya çıkışından itibaren tarih öğretiminin amaçları, kapsamı ve yöntemi hep bir tartışma konusu olmuştur. $\mathrm{Bu}$ dönemde milliyetçiliğin yükselişi, ortaya çıkan ulus devletler, bilimsel (profesyonel) tarihyazım anlayışı ve Avrupa üniversitelerinde oluşturulan tarih programları ile paralel olarak 19. Yy'ın ikinci yarısından itibaren tarih öğretiminin amaçları, yöntemi ve sorunları ile ilgili ilk akademik çalışmalar ortaya çıkmaya başlar. $\mathrm{Bu}$ alanda gerçekleştirilen ilk çalışmalar arasında McLaughlin vd.'nin 1898 tarihli "Okullarda Tarih Araştırması" raporu McManis'in (1900) "Liselerde tarih öğretiminde karşılaşılan zorluklar" başlıklı makalesi, McMurry'nin (1903) "Tarihte Özel Yöntemler (Special Method in History)" kitabı ve 20.yy.' 1 başında The Journal of Education ve The School Review dergilerinde yayınlanan pek çok makale sayılabilir. Ülkemizde II. Meşrutiyetten itibaren başlayan tartışma ve reform çalışmalarında Selim Sabit Efendi, Mustafa Satı Bey, İhsan Sungu ve İsmail Hakkı Baltacıoğlu gibi eğitimcilerin büyük katkıları olmuştur. İki dünya savaşı sonrasında tarih eğitiminin milletler arası anlaşmazlıkları çözmek amacıyla kullanabileceği fikri ortaya 
atılmıştır. $\mathrm{Bu}$ bağlamda tarih ders kitaplarından düşmanlığ1 körükleyici ifade ve anlatıların çıkarılması, barışçıl tarih öğretiminin geliştirilmesini amaçlayan çalışmalar yapılmıştır (Safran ve Ata, 2006, s. 62). 20. Yy.'1n ikinci yarısından itibaren genelde sosyal bilimler, özelde tarihin okul programlarındaki yerinin tartışılır hale gelmesi sonrasında özellikle Coltham ve Fines gibi İngiliz tarih eğitimcilerinin katkısıyla tarih öğretiminde yeni yaklaşımlar geliştirme arayışına girilmesi bu alanda yapılan çalışmalara hız kazandırmıştır (Demircioğlu, 2010, s.13).

Türkiye'de son 40 yılda gerçekleştirilen kongre, sempozyum, kitap ve tez çalışmaları ile tarih eğitimine yönelik çalışmaların büyük bir ivme kazandığını görmekteyiz. Bu alanda geniş etkili ilk çalışma 1975 yılında Türk Felsefe Kurumu'nun yapmış olduğu “Türkiye'de Tarih Eğitimi” sempozyumlarıdır. Bu ilk sempozyumlardan sonra 1994 Buca Sempozyumuna kadar on sekiz yıl süren uzun bir sessizlik ortamı oluşmuştur. Buca Sempozyumu ile belki de ciddi bir ivme kazanan tarih eğitimi ve sorunları üzerine çalışmalar devam etti. 1995'te Boğaziçi Üniversitesi'nde "Tarihte Öteki Sorunu ve Tarih Eğitimi” adıyla bir toplantı gerçekleştirildi. Sonrasında 1998 yılında İstanbul'da, Goethe Enstitüsü ile Almanya'nın Braunschweig kentinde faaliyet gösteren George Eckert Uluslararası Ders Kitapları Enstitüsü ile birlikte bir toplantı düzenlendi. Bu toplantıda Fransız ve Alman tarih ders kitaplarının düzeltilme sürecinde bulunmuş kişiler, bu konu üzerinde sunumlarda bulunmuşlardır. 2010 yılında Atatürk Üniversitesi öncülüğünde başlatılan "Uluslararası Tarih Eğitimi Sempozyumu" düzenli olarak iki yılda bir toplanmaya devam etmektedir.

Türkiye'de Tarih Eğitimi alanında yapılan lisansüstü tezlerin incelenmesi konulu herhangi bir çalışma yapılmamış olmakla birlikte yakın bir alan olan Sosyal Bilgiler Eğitimi alanında benzer çalışmalar karşımıza çıkmaktadır. Bu çalışmalardan ilki Şahin Oruç ve Kadir Ulusoy'un "Sosyal Bilgiler Öğretimi Alanında Yapılan Tez Çalışmaları" isimli (2008) yılında yapıllmış olan ve 2000-2007 yılları arasındaki tez çalışmalarını konu edinen çalışmadır. Bu araştırma ile yazarlar; 2000-2007 yılları arasını kapsayan Sosyal Bilgiler Eğitimi ile ilgili yayınlanan tezler incelenmiş ve tezler ile ilgili eleştirilere ve tespitlere yer verilmiştir. Bir diğer çalışma Ömer Faruk Sönmez, Zihni 
Merey ve Selahattin Kaymakçı tarafından "Vatandaşlık ve İnsan Hakları Eğitimi Alanında Yapılan Yüksek Lisans ve Doktora Tezlerinin Değerlendirilmesi” konulu (2009) yılında çalışmadır. Bu çalışmada Türkiye'de vatandaşlık ve insan hakları eğitimi üzerine yapılan tezler konu ve yöntem açısından durumunu ortaya konulmuştur. $\mathrm{Bu}$ alanda yapılmış olan bir diğer çalışma ise Bülent Tarman, İsmail Acun ve Züleyha Yüksel'in “Sosyal Bilgiler Eğitimi Alanındaki Tezlerin Değerlendirilmesi” başlıklı (2010) çalışmadır. Bu çalışmanın amacı Sosyal Bilgiler alanında yapılmış olan yüksek lisans ve doktora tezlerini ağırlıklı oldukları konulara, yapılış yıllarına, üniversitelere ve hangi araştırma tekniğini kullandığına göre gruplandırılarak incelemektir. Bu alandaki kapsamlı çalışmalardan birisi de Mustafa Şahin, Derya Göğebakan Yıldız ve Ruşen Duman'ın “Türkiye'deki Sosyal Bilgiler Eğitimi Tezleri Üzerine Bir Değerlendirme" konulu (2011) çalışmadır. Bu araştırmada ise Türkiye'de sosyal bilgiler eğitimi ile ilgili olarak 1990-2011 y1lları arasında hazırlanmış olan tezlerin farklı kriterlere göre nasıl bir dağılım gösterdiği değerlendirilmiştir.

Tarih eğitimini konu alan tezlerin incelenmesi bu alanda çalışılan ve çalışılmayan konuların belirlenmesini ve araştırma konusu, araştırma yöntemi, araştırma evreni gibi hususlarda genel eğilimin ortaya konmasını sağlayacaktır. Yine Türkiye'de yapılan lisansüstü tez çalışmalarının yabancı ülkelerde yapılan tezler ile karşılaştırılması hem bu alandaki artılar ve eksilerin görülmesini saylayacak hem de araştırmacılar için yeni çalışma alanları ortaya koyacaktır.

\section{Yöntem}

\section{Araştırmanın Amacı ve Problem Durumu}

Araştırmanın amacı Türkiye'de tarih eğitimi üzerine hazırlanmış tezleri araştırma konusu ve kullanılan yöntemler açısından değerlendirmek ve elde edilen sonuçları PROQUEST veri tabanında yer alan farklı ülkelere ait tarih eğitimi tezleri ile karşılaştırmaktır. Araştırmanın problem cümlesi "Türkiye, ABD ve Kanada'da tarih eğitimi alanında yapılmış tezler belirlenen ölçütlere göre nasıl bir 
dağılım göstermektedir?" şeklinde belirlenmiştir. Araştırmada ayrıca aşağıda yer alan alt problemlere cevap aranmaktadır.

Alt Problemler:

1. Tarih eğitimi alanında Türkiye'de ABD ve Kanada'da yapılan yüksek lisans ve doktora tezleri hangi konular üzerinde yoğunlaşmaktadır?

2. Tarih eğitimi alanında Türkiye'de ABD ve Kanada'da yapılan yüksek lisans ve doktora tezlerinde kullanılan araştırma yöntemi ve veri toplama araçları nelerdir?

3. Tarih eğitimi alanında Türkiye'de ABD ve Kanada'da yapılan yüksek lisans ve doktora tezleri hangi eğitim düzeyine hitap etmektedir?

\section{Verilerin Toplanmast}

$\mathrm{Bu}$ araştırmada Türkiye'de yapılan lisansüstü tezlere ulaşmak amacıyla YÖK tez merkezi ve çeşitli üniversite kütüphanelerinden "Tarih, Tarih Eğitimi, Tarih Öğretimi, Lise Tarih, Ortaokul Tarih, İlkokul Tarih, Tarih Ders Kitapları, Tarih ve Öğretmen" anahtar kelimeleri girilerek ön tarama yapılmıştır. Ön tarama neticesinde ulaşılan tezler ön değerlendirmeye tabi tutularak tarih eğitimi ile ilgili olmayanlar ve tam metin olarak yayınlanmayanlar listeden çıkarılmıştır. Araştırmanın Türkiye ayağı ulaşılan 98 adet yüksek lisans ve doktora tezi üzerinden yürütülmüştür. Uluslararası alanda yapılan tarih eğitimi tezlerine ulaşmak amaciyla PROQUEST'te "History Education, History Teaching, History Instruction, History Teacher, History Textbook, History and Technology" anahtar kelimeleri kullanılarak arama yapılmıştır. İlk arama sonucunda ulaşılan 480 tez ön değerlendirmeye tabi tutularak tarih eğitimi ile ilgili olmayanlar ve tam metin olarak yayınlanmayanlar çıkarılmış ve böylece araştırmanın ABD ve Kanada ayağı ulaşılan 151 adet yüksek lisans ve doktora tezi üzerinden yürütülmüştür. 


\section{Verilerin Analizi}

Araştırma doğrultusunda incelenen yüksek lisans ve doktora tezleri ağırlıklı oldukları konulara, yapılış yıllarına, üniversitelerine, düzeylerine (yüksek lisans ve doktora), kullanılan araştırma türü ve yöntemine, veri toplama araçlarına ve araştırma evrenine göre içerik analizi yöntemi ile analiz edilmişlerdir.

İçerik analizi, verilerin tanımlanmasını yapmak ve verilerin içerisinde saklı olabilecek gerçekleri ortaya çıkarmaya çalışmaktır. İçerik analizi yapılırken şu evrelere dikkat etmek gerekir, birbirine benzeyen verileri belirli kodlar ve temalar dâhilinde birleştirmek, okuyucu kitlesinin anlayacağı bir biçime sokmak ve bu kodlar ve temaların yorumlamasını yapmaktır (Yıldırım, Şimşek, 2011, s. 227). Tanımdan da anlaşıldığı üzere içerik analizi ile yapılan kodlamalar sonucunda elde edilen kavramlardan bir bütünlük oluşturulmaya çalışılmış ve bu araştırma da incelenen tezler dokuz kategoride gruplandırılmıştır.

\section{Bulgular}

Araştırma kapsamında Türkiye'de tarih eğitimi alanında yapılmış ve tam metin olarak erişime açık 84 adet yüksek lisans ve doktora tezine ulaşılmıştır. İncelemeye tabi tutulan bu 84 tez arasında en eski tarihli tez 1996 yılina ait olmakla beraber tam metin olarak erişime açılmayan daha eski tezler de saptanmıştır. Bu çalışma sırasında ulaşılabilen en eski tarih eğitimi tezi M. Fatih Kesler'in 1984 yılında Ankara Üniversitesi, İlahiyat Fakültesi bünyesinde yaptığı yükseköğretimde tarih eğitimini konu alan "Darü'l-Fünun Edebiyat Fakültesinde Tarih Öğretimi ve Son Devir Tarih Hocaları" başlıklı yüksek lisans tezidir. Yine bu alana yapılmış ilk tez çalışmaları arasında Murat Bolat'ın (1989), "Siyasal Toplumsallaşmada Ders Kitaplarının İçeriği ve Etkileri: İnkılap Tarihi Kitaplarının İçerik Çözümlemesi”, Yücel Kabapınar'ın (1991) “Ortaöğretimde (Lise) Tarih Öğretimi: Müfredat Programı ve Ders Kitapları Açısından”, Metin Yaşar'ın (1991) "Lise Tarih Dersi Öğretmen Notlarının Değerlendirilmesi İle İlgili Bir Araştırma”, ve Erdal Aslan'ın (1992) 
"Devrim Tarihi Ders Kitapları" başlıklı yüksek lisans tezleri sayılabilir.

PROQUEST veri tabanında yapılan tarama sonucunda ulaşılan 151 yüksek lisans ve doktora tezi arasında en eski tarihli olanı Simon B. Spradlin'in 1936 tarihli "Studies in the History of History Teaching (Tarih Öğretiminin Tarihçesi Çalışmaları)" başlıklı doktora tezidir. Yazar bu çalışmasında 1834-1936 yılları arasında Amerikan liselerinde tarih öğretiminde kullanılan yöntemlerin gelişimini incelemiştir. $\mathrm{Bu}$ araştırma 19.yy'dan 2016'ya tarih öğretiminde kullanılan yöntemlerin pek fazla değişikliğe uğramadığını göstermesi açısından da önemlidir. Spradlin tez çalışmasında 19. yy.da en sık kullanılan tarih öğretim yöntemleri şöyle belirlenmiştir:

1. Ders kitabı yöntemi (The textbook method): En eski yöntem. Tek bir ders kitabının ana kaynak olarak kullanıldığı, bu kitabın sınıfta öğrenciler tarafından okunduğu ve belli sayfa aralıklarının ödev olarak verildiği yöntem.

a) Ezbere dayalı ders kitabı yöntemi (Memoriter): Ders kitabında verilen bilgilerin verildiği şekilde ezberlenmesi esasına dayanan yöntem. $\mathrm{Bu}$ yöntemin alana özgü dili geliştirdiği savunulmaktadır.

b) Ezbere ve anlamaya dayalı yöntem

c) Ezbere dayılı olmayan ders kitabı yöntemi: Öğrencilerin yazarın verdiği bilgi ve düşünceleri kendi kelimeleri ile açıkladığı yöntem.

2. Düz anlatım yöntemi (The lecture method)

3. Başlık yöntemi (The topical method): Öğrencilere kitabın belli bölümlerinin ödev olarak verilerek öğrencilerden bu bölümlerle ilgili yazılı veya sözlü rapor istenilen öğretim yöntemi.

4. Kaynak yöntemi (The source method): Ana kaynakların derste kullanılması esasına dayanan öğretim yöntemi.

"Laboratuar yöntemi nasıl fen eğitiminde kullanılabilecek tek bilimsel yol ise, tarih eğitimde kullanılacak tek bilimsel yol kaynak metodudur" (Fling and Galdwell, Akt. Spradin, 1936) 
5. Problem yöntemi (The problem method): Geçmişte yaşanan sorun ve problemleri o zamana uygun yöntem ve tekniklerle çözme esasına dayanan öğretim yöntemi

6. Proje yöntemi (The Project method)

7. Ünite Yöntemi (The Unit Method)

Araştırmada Kullanılan Tezlerin Ülkelere Göre Dă̆ılımı

Tablo 1. Araştırmaya Konu Olan Tezlerin Ülke, Üniversite Sayısı ve Eğitim Seviyesine Göre Dağglımı

\begin{tabular}{lccccc} 
& \multicolumn{2}{c}{ Türkiye } & \multicolumn{2}{c}{ ABD \& Kanada } \\
\hline Üniversite & \multicolumn{2}{c}{19} & \multicolumn{2}{c}{77} \\
\hline Düzey & Y.Lisans & & Doktora & \multicolumn{1}{c}{ Y.Lisans-Doktora } \\
\cline { 2 - 6 } & 85 & & 13 & 19 & 132 \\
\hline Toplam & & $\mathbf{9 8}$ & & $\mathbf{1 5 1}$ \\
\hline
\end{tabular}

Bu tabloda Türkiye, ABD ve Kanada'da yapılmış olan Tarih Eğitimi ile ilgili tezlerinin ülkelere göre dağılım tablosu görülmektedir. Bu araştırmaya göre Türkiye'de Tarih Eğitimi ile ilgili yüksek lisans ve doktora alında toplam 98 tez çalışması, ABD'de Tarih Eğitimi ile ilgili yüksek lisans ve doktora alanında toplam 133 tez çalışması, Kanada'da ise Tarih Eğitimi ile ilgili yüksek lisans ve doktora alanında toplam 18 tez çalışmasının yapıldığ 1 , genel toplamda ise Tarih Eğitimi ile ilgili 249 yüksek lisans ve doktora tez çalışmasının yapıldığ 1 görülmektedir. Burada şunu belirtmek gerekir ki tabloda ABD ve Kanada ayrımı tezlerin araştırma evrenini değil bu tezlerin yapıldığı üniversitenin yer aldığı ülkeyi tanımlamaktadır. $\mathrm{Bu}$ tezler arasında Türkiye, Kıbrıs, Bulgaristan, Almanya, Romanya, Polonya, Sirbistan, Moldova, Singapur, İsrail, Kazakistan, Japonya, Güney Kore, Çin, Bhutan, Trinidad-Tobago ve Brezilya gibi farklı ülkelerdeki durumunu araştıran tezler de yer almaktadır. Bu tabloya göre yapılan tezler düzey olarak incelendiğinde, Türkiye'de yapılan tezlerden çoğunluğunun (85) yüksek lisans tezi, 13 tanesinin de doktora tezi olduğu görülmektedir. $\mathrm{ABD}$ ve Kanada üniversitelerinde yapılan tezlere bakıldığında Türkiye'deki oranların tam tersi oranlar görülmektedir. ABD \& Kanada'da yapılan tezlerin çoğunluğu (132) doktora seviyesinde 19 tanesi ise yüksek lisans seviyesindedir. 
Araştırma kapsamında incelenen tezler Türkiye'de 19, ABD ve Kanada'da ise toplam 77 üniversitede bünyesinde yapılmış çalışmalardır.

\section{Üniversiteler}

Araştırmaya Göre En Çok ve En Az Tez Çalışması Yapılan

Tablo 2. Tarih Eğitimi Konulu Tezlerin Üniversiteye Göre Dağılımı

\begin{tabular}{ccc}
\hline & Türkiye & ABD \& Kanada \\
\hline \multirow{2}{*}{ En } & Gazi Üniv. (43) & Stanford Üniv. (9) \\
ço & Marmara Üniv. (19) & Michigan State Üniv. (7) \\
& Atatürk Üniv. (7) & Texas A\&M Üniv. (5) \\
& 9 Eylül Üniv. (5) & Toronto Üniv. (5) \\
& Selçuk Üniv. (5) & Columbia Üniv. (5) \\
En & Sakarya Üniversitesi (1) & Florida Üniversitesi (1) \\
Az & Hacettepe Üniversitesi (1) & New School for Social (1) \\
& Muğla Üniversitesi (1) & Massachussets Üniversitesi (1) \\
& Anadolu Üniversitesi (1) & Calgary Üniversitesi (1) \\
& Frat Üniversitesi (1) & New York State Üniversitesi (1)
\end{tabular}

Araştırma bulgularına göre tarih eğitimi konulu tezlerin üniversitelere göre dağılımı doğal olarak bu alanda yüksek lisans ve doktora programı bulunan üniversiteler lehine artmaktadır. Ancak tarih eğitimi yüksek lisans ve doktora programı bulunan üniversiteler arasında da bu dağılımın homojen olmadığı bu alanda yapılan tez çalışmaların büyük bölümünün Gazi Üniversitesi ve Marmara Üniversitesi bünyesinde gerçekleştirildiği görülmektedir. Oysa ABD ve Kanada'da yaptırılan tez çalışmalarının üniversiteler arasında daha homojen dağıldığı görülmektedir.

\section{Araştırma Konularına Göre Tezlerin Dă̆ılımı}

$\mathrm{Bu}$ çalışmada "code-redoce" tekniğini kullanılarak incelen tezlerin araştırma ana konuları ve alt konuları tespit edilmiş daha sonrasında bir birine yakın ve benzer olanlar bir araya getirilerek toplam 12 ana konu başlığ 1 altında gruplandırılırmıştır. 
Tablo 3. Tarih Eğitimi Tezlerin Araştırma Konusuna Göre Dağılımı

\begin{tabular}{|c|c|c|c|c|c|}
\hline \multicolumn{6}{|c|}{ Konu Ana Başlıkları } \\
\hline & \multicolumn{2}{|c|}{ Türkiye } & \multicolumn{2}{|c|}{ ABD\&Kanada } & Toplam \\
\hline & $\mathbf{f}$ & $\%$ & $\mathbf{f}$ & $\%$ & $\mathbf{f}$ \\
\hline Öğretim Yöntem ve Teknikleri & 26 & 25 & 18 & 11 & 47 \\
\hline Öğretim Tek. ve Materyalleri & 15 & 14 & 27 & 16 & 40 \\
\hline Alan Bilgisi Ĕgitimi & 9 & 9 & 8 & 5 & 18 \\
\hline Beceri Eğitimi & 8 & 8 & 18 & 11 & 26 \\
\hline Değerler Eğitimi & 3 & 3 & 17 & 10 & 20 \\
\hline Tutum / Görüş & 21 & 20 & 20 & 12 & 41 \\
\hline Program ve Ders Kitapları & 9 & 9 & 22 & 12 & 29 \\
\hline Ĕ̆itim / Tarih Ĕ̆t. Yaklaşımları & 2 & 2 & 7 & 4 & 9 \\
\hline Ö̈̆gretmen Eğitimi / Yeterlikleri & 1 & 1 & 17 & 10 & 18 \\
\hline Genel Durum ve Sorunlar & 5 & 5 & 11 & 6 & 16 \\
\hline Ölçme Değerlendirme & 0 & 0 & 2 & 1 & 2 \\
\hline Tarih Ĕgitiminin Tarihi & 4 & 4 & 4 & 2 & 8 \\
\hline Toplam & \multicolumn{2}{|c|}{103} & \multicolumn{2}{|c|}{171} & $274^{*}$ \\
\hline
\end{tabular}

$\mathrm{Bu}$ araştırmaya göre Türkiye'de Tarih Eğitimi ile ilgili çalışılmış olan konu başlıklarına göre en fazla çalışılan konuların başında öğretim yöntem ve teknikleri (\% 25) ve öğretmen ve öğrenci farklı alt konulara yönelik tutum ve görüşlerinin incelendiği araştırmalar (\% 20) olduğu görülmektedir. ABD ve Kanada'da ise tarih eğitimi ile ilgili çalışılmış olan konu başlıklarına göre en fazla çalışılan konuların başında öğretim teknoloji ve materyalleri (\% 16), program ve ders kitapları (\% 12), tutum / görüş (\%12) gibi konuların olduğu görülmektedir. Bu tablodan Türkiye'de öğretim yöntemi, öğretim teknolojileri-materyalleri ve görüş araştırmalarında bir yoğunlaşma olduğu bu üç alanda yapılan tezlerin tüm tezlerin beşte üçünü oluşturduğu anlaşılmaktadır. Diğer taraftan ülkemizde beceri eğitimi, değerler eğitimi, öğretmen yeterlikleri, eğitim yaklaşımları ve

\footnotetext{
* Bu tablodaki toplamın araştırmada incelenen toplam tez sayısı olan 249'dan farklı olmasının nedeni bazı tezlerde araştırma konusunun birden çok olmasıdır.
} 
ölçme değerlendirme gibi konularda uluslararası alanla kıyasla daha az araştırma yapıldığı görülmektedir. Türkiye'de tarih eğitim tezlerinde en az çalışılan konulara bakıldığında ölçme-değerlendirme konu başlığının hiç çalışılmadığı, öğretmen eğitimi / yeterlilikleri konusunda bir (1), eğitim / tarih eğitimi yaklaşımları konusunda iki (2) ve değerler eğitimi konusunda üç (3) tez çalışmasının yapıldığı görülmektedir. ABD ve Kanada'da tarih eğitimi ile ilgili çalış1lmış konu başlıklarına göre az çalışılmış ya da hiç çalışılmamış konulara bakıldığında ölçme değerlendirme konu başlığı altında iki (2) ve tarih eğitiminin tarihi konusunda yine iki (2) tez çalışması yapıldığı görülmektedir.

\section{Araştırma Alt Konularına Göre Tezlerin Dağılımları}

Araştırma kapsamında ülkemizde incelenen tarih eğitim tezlerinde en çok çalışılan konulardan biri olan Öğretim Yöntem ve Teknikleri alanında ele alınan yöntemler arasında "Issbirlikli Öğrenme (4), Drama (3), Sözlü Tarih (3), Çoklu Zekâ Kuramı (2), Kanıt Temelli Ögretim (2), Not Alma Tekniği (2), Yerel Tarih, Problem Çözme, Ayrıntı Oluşturmacı Yaklaşım, 4MAT Modeli, Öğrenme Stilleri, Araştırma İnceleme, Sunuş, Buluş, Akademik Çelişki, Aktif Yöntem, Anlamlandırma, Örgütleme ve Tekrar" yöntemlerinin yer aldığı görülmüştür. $\mathrm{Bu}$ konuda $\mathrm{ABD}$ ve Kanada'da yapılan tezlerde ise "Probleme dayalı ögretim (2), Eleştirel Öğretim, Tartışmalı (Hassas) konuların ögretimi, Fakir öğrencilere yönelik metotlar, Kaynă̆a dayalı soru çözümü, Araştırmaya dayalı ögretim, Karşılaştırmalı ögretim, Tam öğrenme, Duyguların harekete geçirilmesi” gibi yöntemlerin ele alındığı saptanmıştır.

Ülkemizde tarih eğitiminde öğretim teknolojileri ve materyaller kullanımını konu alan tezlerde; "Belge - Ana kaynak (4), Müze ve tarihi mekânlar (4), Karikatür (2), Harita, Fotoğraf, Sunum araçlart, Belgesel, Filmler, Kavram Haritasl, Roman, Biyografi ve Resimli öykü" gibi farklı materyaller incelenmiştir. Aynı konuda ABD ve Kanada'da yapilan tezlerde ise "Belge - Ana kaynak (3), Simülasyon, Tarihi nesne (2), Çevrimiçi arşiv (2), Uzaktan öğretim (2), Dijital medya yapımı (2), Müze ve tarihi mekânlar (2), Teknoloji destekli eğitim (2), Web-tabanlı ögrenme, Bilgisayar oyunları, Teknoloji 
entegrasyonu, Öykü, Bilgisayar destekli iletişim, Görseller, Sanat (Resim, müzik, şiir) ve Film" gibi farklı eğitim teknolojisi ve materyalinin incelendiği saptanmıştır.

Türkiye'de değerler eğitimi konusunda yapılan üç tezde sadece "Hoşgörü (2) ve Demokratik tutum" değerleri üzerinde durulmuşken ABD ve Kanada'da bu alanda daha fazla çalışma yapılmış ve bu çalışmalarda "Milli kimlik (7), Vatandaşlık (3) Hoşgörü, Antimilliyetçilik, Çok kültürlülük, Vatanperverlik, Eleştirel vatanperverlik, Yorumlayıcı erdemler, Demokratik vatandaşlık, Aktif vatandaşlık" gibi pek çok değer ele alınmıştır ve incelenmiştir.

\section{Kullanılan Yönteme Göre Tezlerin Dă̆ılımları}

Tablo 4. Tarih Eğitimi Tezlerinin Kullanılan Araştırma Yöntemine Göre Dağılımı

\begin{tabular}{lcccccc}
\hline \multirow{2}{*}{ Yöntem } & \multicolumn{2}{c}{ Türkiye } & \multicolumn{2}{c}{ ABD \& } \\
Kanada & \multirow{2}{*}{ Toplam } \\
\cline { 2 - 5 } & & f & $\mathbf{\%}$ & $\mathbf{f}$ & $\mathbf{\%}$ & \\
\hline Nicel & 52 & 53 & 12 & 8 & 64 \\
Nitel & 35 & 36 & 119 & 79 & 154 \\
Karma & 11 & 11 & 20 & 13 & 31 \\
\multicolumn{2}{c}{ Toplam } & $\mathbf{9 8}$ & & $\mathbf{1 5 1}$ & & $\mathbf{2 4 9}$ \\
\hline
\end{tabular}

Araştırma kapsamında Türkiye'de tarih eğitimi alanında yapılmış tezlerin büyük çoğunluğunda (\% 53) nicel araştırma yöntemlerinin kullanıldığı görülmektedir. 2008 yılına kadar yapılan tezlerde nicel yöntemle yapılan tezlerin sayısı her zaman daha yüksektir. 2008 yılından itibaren yapılan tezlerde ise nitel yöntemin daha ağır bastığı görülmektedir. ABD ve Kanada üniversitelerinde yapılan tarih eğitimi tezlerinin büyük çoğunluğunda (\%79) nitel araştırma yöntemleri kullanılmıştır. Türkiye'deki durumun aksine uluslararası tezlerde nicel araştırma yöntemlerinin kullanılma oranı sadece \% 8'dir. Bu tablo Türkiye'de tarih eğitimi üzerinde yapılan tez çalışmalarının henüz gelişme aşamasında olduğu bu nedenle genel durumu ortaya koymayı amaçlayan tanımlayıcı araştırmaların ağır bastığı, ABD ve Kanada üniversitelerinde ise sorunları daha derinlemesine inceleyen, "Niçin" "Nasıl" sorularına cevap arayan açıklayıcı araştırmaların yapılmaya çalışıldığını ortaya koymaktadır. 
Tarih Eğitimi Tezlerinde Kullanılan Veri Toplama Araçları

Tablo 5. Tarih Eğitimi Tezlerinin Kullanılan Veri Toplama Araçlarına Göre Dağılımı

\begin{tabular}{lcccc}
\hline & \multicolumn{2}{c}{ Türkiye } & \multicolumn{2}{c}{ ABD \& Kanada } \\
\hline & f & \% & f & $\%$ \\
Anket & 27 & 28 & 40 & 26 \\
Makale, belge, ders kitabı, pro- & 24 & 24 & 38 & 25 \\
gram incelemesi & & & & \\
Görüsşme & 15 & 15 & 91 & 60 \\
Gözlem & 10 & 10 & 60 & 40 \\
Başarı Testi & 12 & 12 & 14 & 9 \\
Ölçek & 11 & 11 & 9 & 6 \\
Çoktan seçmeli soru & 11 & 11 & 1 & 1 \\
Öğrenci Çalışmaları (Ödev, Pro- & 2 & 2 & 31 & 21 \\
je, Çalışma Kâğıdı, Web-sitesi, & & & & \\
Video, Kompozisyon, Öykü vs.) & & & & \\
Kişisel bilgi formu & 1 & 1 & -- & -- \\
Sesli düşünme protokolü & --- & -- & 8 & 5 \\
Açık uçlu sorular & -- & -- & 3 & 2 \\
& & & & \\
Görsel analiz & -- & -- & 2 & 1 \\
Portfolyo & -- & -- & 1 & 1 \\
Grup tartışması & -- & -- & 1 & 1 \\
Ăğırlıklı not ortalaması & -- & -- & 1 & 1 \\
Derse katılım tablosu & -- & -- & 1 & 1 \\
Film analizi & -- & -- & 1 & 1 \\
\hline
\end{tabular}

Türkiye'de yapılan tarih eğitimi tezlerinde en çok tercih edilen veri toplama aracı ankettir (\% 28). Bunu sırasıyla literatür taraması (\% $24)$, görüşme ( $\% 15)$ ve başarı testi ( $\% 12)$, takip etmektedir. ABD ve Kanada üniversitelerinde yapılan tarih eğitim tezlerinde ise en çok tercih edilen veri toplama aracı görüssmedir (\% 60). Bunu sirasıyla gözlem (\% 40), anket ( $\%$ 26) ve makale, belge, ders kitabı, program incelemesi (\% 25) takip etmektedir. Tablo 4'te görüleceği üzere ABD ve Kanada üniversitelerinde yapılan "tezlerde sesli düşünme, 
portfolyo, görsel analiz, film analizi, küçük grup tartışması" gibi Türkiye'de yapılan tezlerde hiç kullanılmamış farklı veri toplama araçları kullanılmıştır. Yine bu tablodan çıkarılabilecek bir başka sonuç ise Türkiye'de yapılan tezlerde tez başına 1,25 farklı veri toplama araci kullanılırken, ABD ve Kanada'da yapılan tezlerde bu oranın tez başına 2,02'ye çıkmasıdır.

Hitap Edilen Ĕgitim Düzeyine Göre Tezlerin Dağılımı

Tablo 6. Hitap Ettiği Eğitim Düzeyine Göre Tezlerin Dağılımı

\begin{tabular}{lccc}
\hline \multicolumn{1}{c}{ Eğitim Düzeyi } & Türkiye & $\begin{array}{c}\text { ABD \& } \\
\text { Kanada }\end{array}$ & Toplam \\
\hline İlkokul & 8 & 20 & 28 \\
Ortaokul & 14 & 13 & 27 \\
Lise & 44 & 80 & 124 \\
Yüksek Öğretim & 5 & 6 & 11 \\
Yetişkin (Ömür boyu) & 0 & 7 & 7 \\
\hline
\end{tabular}

Araştırma kapsamında incelenen tarih eğitimi tezlerinin ağırlıklı olarak lise düzeyine yönelik olduğu en az çalışmanın ise yetişkinlerin (Ömür boyu) eğitimi çerçevesinde yapıldığ 1 görülmüştür. ABD ve Kanada üniversitelerinde yapılan tez çalışmalarına kıyasla Türkiye'de yapılan tezlerde ilkokul seviyesine yönelik daha az tez yapıldığı yetişkinlerin eğitimi veya ömür boyu öğrenme alanında ise hiç çalışma yapılmadığı saptanmıştır.

\section{Sonuç ve Tartıșma}

19. yy'ın ikinci yarısında modern tarih eğitimine geçilmesiyle beraber Türkiye'de bu alanda ilk eserler ortaya konmaya başlanmıştır. Ancak tarih eğitimi üzerine yapılan tez çalışmaları nispeten daha yenidir. $\mathrm{Bu}$ alanda yapılan çalışmalar geçtiğimiz 30 yılda giderek hızlanan bir ivme yakalamıştır. Araştırma kapsamında incelenen tezler yıllara göre değerlendirildiğinde Türkiye'de yapılan tarih eğitimi tezi sayısının giderek arttığı görülmüştür. Bu alanda ortaya konan kongre, kitap, makale ve tez çalışmalarındaki artış ülkemizde tarih eğitiminin geleceği açısından sevindiricidir.

Türkiye'de yapılan tezlerin araştırma konularına bakıldığında tarih eğitiminde farklı yöntem ve materyalleri denemeyi amaçlayan 
böylece tarih eğitiminde var olan sorunları gidermeyi veya azaltmayı amaçlayan tezlerin çoğunlukta olduğu görülmektedir. $\mathrm{Bu}$ durum akademisyenler arasında tarih öğretiminde geleneksel anlayışın dışına çıkılarak yeni yaklaşımları benimsemek yönünde bir eğilim olduğunu göstermesi açısından sevindiricidir. Buna karşın uluslararası tezlerle karşılaştırıldığında tutum/görüş araştırmaların daha fazla öğretmen yeterlikleri, ölçme değerlendirme, değer ve beceri eğitimi çalışmalarının ise daha az yapıldığı görülmektedir. Beceri eğitimi ile ilgili çalışmaların azlığı ülkemizde yapılandırmacı eğitim sisteminin daha geç benimsenmesi ile açıklanabilir. Ancak son dönemde uygulanan tarih programlarında önemli bir yer tutan tarihsel düşünme veya tarihçilik becerilerinin öğretimi ve ölçülmesine yönelik çalışmaların artması teorinin pratiğe geçmesi ve ülkemizde tarih eğitiminin amacına ulaşması açısından önemlidir.

Türkiye'de yapılan tarih eğitim tezlerinde ağırlıklı olarak nicel araştırma yöntemlerinin benimsendiği görülmektedir. Oysa eğitim araştırmalarında son y1llardaki eğilim nitel yöntemlerin kullanılması yönündedir. Araştırma kapsamında incelediğimiz uluslararası tezlerin \% 92'sinde nitel ve karma araştırma yöntemlerinin benimsenmesi bunun bir göstergesidir. Türkiye'de son on yılda bu yönde bir değişim yaşanmış ve 2008 yılından itibaren yapılan tezlerde nitel araştırma yöntemleri daha çok kullanılır olmuştur.

Araştırma yöntemine bağlı olarak ülkemizde tarihi eğitimi üzerine yapılan her 100 tezin 62'sinde anket, ölçek, başarı testi, çoktan seçmeli soru gibi nicel veri toplama araçları kullanılmıştır. Buradan araştırmacıların olayları dışarıdan değerlendiren, araştırma ortamına dâhil olmayan bir role büründüğünü görmekteyiz. Yurtdışında yapılan tarih eğitim tezlerinde ise görüşme (her 100 tezin 60'sında), gözlem (her 100 tezin 40'ında), öğrenci çalışmalarının değerlendirilmesi, sesli düşünme protokolü ve grup tartışması gibi ancak sinıfta birebir uygulanabilecek veri toplama yöntemlerinin ağırlıklı olarak kullanıldığı görülmektedir. Bu araştırmacıların büyük çoğunluğu doğrudan öğretmen rolü oynamış, okullara giderek öğretmen ve öğrencileri yerinde gözlemlemiş, onlarla görüşme veya farklı etkinlikler yapmıştır. Araştırmacının üslendiği bu rolden "olayları doğal ortamında gerçekçi ve bütüncül bir şekilde ortaya koyamaya" (Yıldırım ve Şimşek, 2011, s.14) çalıştığı anlaşılmaktadır. 
Bu bakış açısı yukarıda bahsettiğimiz gibi teorinin pratiğe dönüşmesi, sorunların çözümü için ortaya atılan hipotezlerin sınanması ve böylece tarih eğitiminde yaşadığımız sorunların giderilebilmesi için önemlidir.

Son olarak Türkiye'de akademik yazım kurallarına açısından tarih eğitimi tezlerinin olumlu bir gelişim sürecinde olduğu görülmektedir. Araştırma kapsamında incelediğimiz tezlerden sadece sekiz tanesinde yöntem bölümüne yer verilmemiştir. Bunların daha ziyade 90'lı yıllara ait tezler olduğunu son 15 yılda yapılan tezlerin bu açıdan daha iyi düzeyde olduğunu belirtmek gerekir. Eğitim Bilimleri Enstitülerinin son yıllarda benimsediği tez yazım kılavuzları ile akademik tez yazımını içerik ve görünüm açısından belli kurallara oturtması bu açıdan olumlu bir gelişme olmuştur.

\section{Kaynaklar}

Akyüz, Y. (2014). Türk Eğitim Tarihi (26. Bask1). Ankara: Pegem.

Aslan, E. (1992). Devrim tarihi ders kitapları (Yayımlanmamış Yüksek Lisans Tezi). Dokuz Eylül Üniversitesi Atatürk İlkeleri ve İnkılap Tarihi Enstitüsü Atatürk İlkeleri ve İnkilap Tarihi Anabilim Dalı, İzmir.

Bolat, M. (1989). Siyasal toplumsallaşmada ders kitaplarının içeriği ve etkileri: Inkılap tarihi kitaplarının içerik çözümlemesi. (Yayımlanmamış Yüksek Lisans Tezi) İstanbul Üniversitesi, Sosyal Bilimler Enstitüsü. İstanbul.

Breisach, E. (2009). Tarihyazımı. H. Kocaoluk (Çev.) İstanbul: Yapı Kredi.

Demircioğlu, İ.H. (2014). Türkiye'de tarih eğitimi: sorunlar ve çözüm önerileri. Yeni Türkiye, 1176-1186.

Demircioğlu, İ.H. (2012). Osmanlı Devletinde tarih yazımının tarih öğretimi üzerine etkileri. Milli Ĕgitim, S. 193, s.115-125.

Demircioğlu, İ.H. (2010). Tarih ögretiminde ögrenci merkezli yaklaşımlar (3. Bask1), Ankara: An1.

Documents upon Napoleon and Education, (t.y.). http://www.napoleonseries.org/research/government/legislation/c education.html. Erişim: 10.06.2016.

Kabapınar, Y. (1991). Müfredat programı ve ders kitapları açısından ortaöğretim'de (lise) tarih ögretimi. (Yayınlanmamış Yüksek lisans Tezi) Dokuz Eylül Üniversitesi Sosyal Bilimler Enstitüsü, İzmir.

Kesler, F. (1984). Darül-fünun edebiyat fakültesinde tarih ögretimi ve son devir tarih hocaları (Yayımlanmamış Yüksek Lisans Tezi). Ankara Üniversitesi İlahiyat Fakültesi Türk-İslam Edebiyatı Anabilim Dalı, Ankara.

McLaughlin, A.C., Adams, H.B., Fox, G.L., Hart, A.B., Haskins, C.H., Salmon, L.M. ve Stephens, H.M. (1898). The study of history in schools: A report to the american historical association by the committee of seven. 
https://www.historians.org/about-aha-and-membership/aha-history-andarchives/archives/the-study-of-history-in-schools (Erişim: 11.06.2016).

McManis, J. T. (1900). Some difficulties in teaching history in a small high school. The School Review, Vol. 8, No. 9 (Nov., 1900), pp. 535-539.

McMurry, C. A. (1903). Special method in history; a complete outline of a course of study in history for the grades below the high school. New York: Macmillan.

Oruç, Ş. ve Ulusoy, K. (2008). Sosyal bilgiler öğretimi alanında yapılan tez çalışmaları. Selçuk Universitesi, Ahmet Keleşoğlu Eğitim Fakültesi Dergisi, S. 26, s.121-132.

Öztürk, İ.H. (2015). Bilimsel (modern) tarihten parçalanmış (postmodern) tarihe. A. Şimşek (Edt.) Tarih Nasıl Yazılır? Tarih Yazımı için Çağdaş bir Metodoloji. İstanbul: Tarihçi.

Safran, M. (2008). 21. Yüzyllda kimlik, vatandaşlık ve tarih eğitimi. İstanbul: Yeni İnsan.

Safran, M. ve Ata, B. (2006). Barış̧̧ı tarih öğretimi üzerine çalışmalar. Tarih Eğitimi Makale ve Bildiriler, Ankara: Gazi Kitapevi.

Sönmez, Ö.F., Merey, Z. ve Kaymakcı, S. (2009). Vatandaşlık ve insan hakları eğitimi alanında yapılan yüksek lisans ve doktora tezlerinin değerlendirilmesi. Uluslararası Avrupa Birliği, Demokrasi, Vatandaşlık ve Vatandaşlık Ĕ̆itimi Seтроzуити, Uşak Üniversitesi Avrupa Birliği Araştırma ve Uygulama Merkezi, 28-30 Mayis, 2009.

Spradlin, S.B. (1936). Studies in the history of history teaching (Yayımlanmamış Doktora Tezi) The University of Oklahoma, Graduate School: Canute.

Şahin, M., Göğebakan-Yıldız, D. ve Duman, R. (2011). Türkiye'deki sosyal bilgiler eğitimi tezleri üzerine bir değerlendirme. Journal of Social Studies Education Research, 2 (2), 96-121.

Şirin, İ. (2015). Genel tarih anlayışları. A. Şimşek (Edt.) Tarih Nasıl Yazılır? Tarih Yazımı için Çağdaş bir Metodoloji. İstanbul: Tarihçi.

Strandling, R., 2003, 20. Yüzyıl Avrupa Tarihi Nasıl Öğretilmeli, İstanbul: Tarih Vakfi Yayınları.

Tarman, B., Acun, İ. ve Yüksel, Z. (2010). Sosyal bilgiler eğitimi alanındaki tezlerin değerlendirilmesi. Gaziantep Üniversitesi Sosyal Bilimler Dergisi, 9 (3), s. 725-746.

Yaşar, M. (1991). Lise tarih dersi ögretmen notlarının değerlendirilmesi ile ilgili bir araştırma (Yayımlanmamış Yüksek Lisans Tezi). Hacettepe Üniversitesi, Sosyal Bilimler Enstitüsü, Ankara.

Yıldırım, A., Şimşek, H. (2011). Sosyal bilimlerde nitel araştırma yöntemleri. Ankara: Seçkin.

\section{Purpose}

\section{Extended Summary}

Reviewing dissertations on one field would be quite beneficial to identify overall framework, trend and focus of research in that field. Therefore, the purpose 
of this research is to evaluate history education dissertations submitted to council of higher education (YOK) thesis center and PROQUEST database in order to make comparison between national and international dissertations in term of their topics and research methods. This comparison is expected to help identify strength and weakness of Turkish history education compared to international studies in the field.

Within this scope this study aims to clarify following research questions;

1. What is the focus of research on those master's and doctoral dissertations in the field of history education conducted in the USA, Canada and Turkey?

2. What research methods and data collection tools they use?

3. Which educational level they target?

\section{Method}

This study was designed as a qualitative descriptive study. Required data was gathered from Council of Higher Education (YOK), "National Dissertation Center" and PROQUEST databases through computer-aided screening method by using various search terms such as; "History Education, History Teaching, History Instruction, History Teacher, History Textbook, History and Technology". Computer-aided screening method brought up hundreds of dissertations. During preliminary assessment the ones that not related with history education/teaching nor published in full text have been removed from the list. The final assessment conducted on 98 dissertations from Turkish Universities and 151 dissertations from US and Canadian universities. Here it should be noted that some of these dissertations from US and Canadian universities were conducted by international students on a population from various countries. These countries include Turkey, Cyprus, Bulgaria, Germany, Romania, Poland, Serbia, Russia, Singapore, Israel, Kazakhstan, Japan, South Korea, China, Bhutan, Trinidad - Tobago and Brazil.

Compiled dissertations were evaluated using content analysis method according to country, date, university, level (masters or doctorate), topic, research method and data collection instruments.

\section{Results}

The oldest dissertation on history education in Turkey that can be reached during this study was a master's thesis prepared by M. Fatih Kesler in 1984, entitled; "History teaching at Dar Al-funun (Istanbul University), Faculty of Art and the last era faculty members". Within 151 master's and doctoral dissertation found in the PROQUEST database the oldest one was dated 1936, written by Simon B. Spradlin and entitled; "Studies on the history of history education".

Research topics: According to this study, the most studied research topic observed in Turkey is "teaching methods and techniques" $(25 \%)$, and "teachers' and students' attitudes" toward various issues in history teaching (20\%). On the other hand, the most studied topics observed in the US and Canada is "instructional technology and materials" (16\%), "curriculum and textbooks" $(12 \%)$, and attitudes toward various issues (12\%). "Assessment and evaluation (0), teacher training / 
qualifications (1), history education approaches (2), and values education (3)" are the least studied topics in Turkish universities whereas "assessment and evaluation (2), history of history education (2)" are the least studies topics in the US and Canadian universities.

Methods: The majority of dissertations in the field of history education in Turkey was used quantitative research methods (53\%), whereas the vast majority of dissertations in the US and Canada employ qualitative methods (79\%). Unlike the situation in Turkey, the rate of international dissertations employed quantitative research methods is only 8 percent.

Data collection tools: Questionnaire (28\%), literature review (24\%), interview $(15 \%)$, and achievement tests $(12 \%$ are the most common data collection tools used in Turkey whereas interview $(60 \%)$, (40\%), questionnaire $(26 \%)$, and document, textbooks, program review $(25 \%)$ are more common in US and Canada. Also it has been observed that international dissertations use some data collection methods which are never used in Turkish dissertations such as "think aloud, portfolio, visual analysis, video analysis, and small group discussion".

\section{Discussion and Conclusion}

Study shows that the number of dissertation on history education in Turkey has been increasing in the last 30 years. Teaching methods and attitudes are the two mostly studied subject in Turkish dissertations on the other hand educational technology, curriculum and textbooks are the mostly studies subject in international dissertations. This show majority of the dissertations in Turkey aiming to try new teaching methods and materials in history classrooms in order to reduce or resolve common issues and problems in history teaching.

Study also shows Turkish researchers are more often relied on quantitative research methods and data collection tools, by contrast qualitative research methods and related data collection instruments are mostly used by international researchers. $92 \%$ of the international dissertations that analyzed in this study adopted qualitative or mixed research methods. It has been observed that Turkish researchers are also following this international trend in recent years hence number of dissertations employed qualitative methods has been increasing rapidly since 2008 .

Along with research methods $62 \%$ of the dissertations used quantitative data collection instruments such as survey, scale, achievement test, multiple choice questions in Turkey. That means most of the Turkish researchers decided to examine issues in history teaching from a distance and played non-participant observer role. On the other hand most of the international researchers preferred to play participant observer role in their research and used those data collection instruments that can only be used in classroom, on-to-one with students such as interview $(60 \%)$, observation $(40 \%)$, evaluation of student work, think-aloud protocol, and group discussion. 